\title{
Effect of Quenching Temperature on Microstructure and Mechanical Properties of Q1030 Steel
}

\author{
Jianjing Wang1,2, Yonglin Kang1, Hao Yu1 ${ }^{1}$, Wenying Ge ${ }^{2}$ \\ ${ }^{1}$ University of Science and Technology Beijing, Beijing, China \\ ${ }^{2}$ Laiwu Branch of Shandong Iron \& Steel Co. Ltd., Jinan, China \\ Email: bandaisuo@126.com
}

How to cite this paper: Wang, J.J., Kang, Y.L., Yu, H. and Ge, W.Y. (2019) Effect of Quenching Temperature on Microstructure and Mechanical Properties of Q1030 Steel. Materials Sciences and Applications, 10, 665-675.

https://doi.org/10.4236/msa.2019.1010047

Received: September 29, 2019

Accepted: October 25, 2019

Published: October 28, 2019

Copyright $\odot 2019$ by author (s) and Scientific Research Publishing Inc. This work is licensed under the Creative Commons Attribution International License (CC BY 4.0).

http://creativecommons.org/licenses/by/4.0/

\begin{abstract}
In this paper, the law of austenitic grain growth gfg is studied under different heating temperature and insulation time, the suitable grain growth model is established, and the regression calculation method is introduced to verify the correctness of the model. The effect of quenching temperature on the microstructure and strength of steel was studied, and it was proved that the quenching temperature had a significant effect on the microstructure and mechanical properties of Q1030 steel. At the quenching temperature of $880^{\circ} \mathrm{C}$ $950^{\circ} \mathrm{C}$, with the increase of austenitizing temperature, the hardness and strength of Q1030 steel gradually increased, reaching the maximum value at $950^{\circ} \mathrm{C}$. During quenching at $950^{\circ} \mathrm{C}-1100^{\circ} \mathrm{C}$, the hardness and strength of Q1030 steel gradually decreased with the increase of austenitic temperature.
\end{abstract}

\section{Keywords}

Heating Temperature, Austenitic Grain, Microstructure, Strength

\section{Introduction}

The heat treatment process is a very critical link for the production of high-strength steel plates. The heat treatment process directly determines the final performance of the steel plates. The formulation of a reasonable heat treatment process is the key to the production of high-performance quality quenched and tempered steel plates. The Q1030 ultra-high strength steel is generally tempered. The quenching process is a very important part. In particular, the heating temperature and insulation time of quenching will directly affect the original austenite grain size and uniformity of high-strength steel, and it will also have an impor- 
tant influence on the dissolution distribution of alloying elements in steel, and affected the martensite strip beam size after the phase transition [1]. The uniform and small original austenite grains help to form uniform and small phase transition structures during subsequent phase transitions, laying the foundation for excellent comprehensive performance [2]. At present, the effect of quenching temperature on austenite grain size of Q1030 ultra-high strength steel has only been qualitatively studied, and no accurate prediction has been reported. The low quenching temperature will lead to incomplete austenitization or incomplete dissolution of alloy elements and uneven distribution. Too high quenching temperature will lead to larger austenite grains, which will lead to unstable mechanical properties of ultra-strong steel Q1030 after heat treatment.

Many steel mills in China have begun to study the relationship between quenching temperature on the structure and performance of high-strength steel. Zhaoyanqing [3] and others of the Hegang Group Research Institute have studied the effect of quenching temperature on the microstructure and mechanical properties of $780 \mathrm{MPa}$-grade hydropower steel. The effects of quenching temperature on the microstructure and properties of $780 \mathrm{MPa}$ high strength steel were obtained, and the best heat treatment technology was put forward, the performance of the steel plate has greatly improved and achieved very significant results.

In this paper, a series of laboratory researches on the quenching and heating system of the Q1030 ultra-high strength have been made, the grain growth model has been established, and the regression calculation method has been introduced to verify the correctness of the model. Some key parameters in actual production were simulated. In this paper, the heat treatment system of Q1030 super high strength engineering machinery steel is studied in laboratory, and some key parameters in actual production are simulated. The evolution of the microstructure and strength of heat treatment at different austenitic temperatures and the influence of alloying elements on tissue transformation were studied, which provided a basis for the actual production of Q1030 ultra-high strength steel plates.

\section{Effect of Quenching Temperature on Austenitic Grain Size of Q1030 Steel}

\subsection{Effect of Quenching Temperature on Austenite Grain Growth}

The test material uses a $20 \mathrm{~mm}$ thick hot rolling plate provided by Lai wu Steel to avoid flame cutting and edge areas. A number of small samples of $20 \mathrm{~mm} \times 20$ $\mathrm{mm} \times 20 \mathrm{~mm}$ were removed by wire cutting. Its composition is shown in Table 1. The thermal treatment tests of the test steel were carried out in the SX-4-10 box resistor furnace and the temperature was heated to $900^{\circ} \mathrm{C}, 950^{\circ} \mathrm{C}, 1000^{\circ} \mathrm{C}$,

Table 1. Chemical composition of Q1030 steel (wt\%).

\begin{tabular}{ccccccccc}
\hline $\mathrm{C}$ & $\mathrm{Si}$ & $\mathrm{Mn}$ & $\mathrm{Cr}$ & $\mathrm{Ni}$ & $\mathrm{Mo}$ & $\mathrm{Cu}$ & $\mathrm{Ti}$ & $\mathrm{Nb}$ \\
\hline $0.16-0.18$ & $0.3-0.4$ & $1.1-1.3$ & $0.38-0.42$ & $0.28-0.32$ & $0.48-0.55$ & $0.35-0.41$ & $0.015-0.025$ & $0.015-0.025$
\end{tabular}


$1050^{\circ} \mathrm{C}, 1100^{\circ} \mathrm{C}$ and $1150^{\circ} \mathrm{C}$, the temperature control accuracy is $\pm 5^{\circ} \mathrm{C}$, and the insulation time is $10 \mathrm{~min}, 20 \mathrm{~min}, 30 \mathrm{~min}, 40 \mathrm{~min}$, and $50 \mathrm{~min}$, respectively. After heat preservation to a predetermined time, water quenching is used immediately to retain the original austenite crystal boundary. After quenching, the sample is ground and polished, and then eroded with an erosive agent. After the original austenite grain boundary appears, the austenitic grain size is determined by the linear intercept method. The number of grains measured is not less than 140.

The austenitic grains of experimental steel at $850^{\circ} \mathrm{C}, 950^{\circ} \mathrm{C}, 1050^{\circ} \mathrm{C}$ and $1150^{\circ} \mathrm{C}$ are kept warm for $30 \mathrm{~min}$ as shown in Figure 1 . It can be seen from the figure that austenite grain size increases gradually with the increase of heating temperature. When the heating temperature is at $850^{\circ} \mathrm{C}$, the average size of austenite grains is about $11 \mu \mathrm{m}$, and the grain size distribution is more uniform; When the heating temperature rises to $950^{\circ} \mathrm{C}$, the average size of austenite grains gradually grows to about $17 \mu \mathrm{m}$; When the heating temperature is increased from $950^{\circ} \mathrm{C}$ to $1000^{\circ} \mathrm{C}$, because the heating temperature is low at this time, the second phase particles of $\mathrm{Nb}$ and $\mathrm{Ti}$ in the test steel are distributed in the austenite grains, strongly preventing austenite grains from growing. So austenite grains grow slowly. When the heating temperature is increased to $1050^{\circ} \mathrm{C}$, the tendency of austenitic grains to grow up becomes very obvious. The average grain size grows to about $34 \mu \mathrm{m}$. The austenitic grains have large differences in size and have a certain degree of mixed crystals; This is because when the temperature
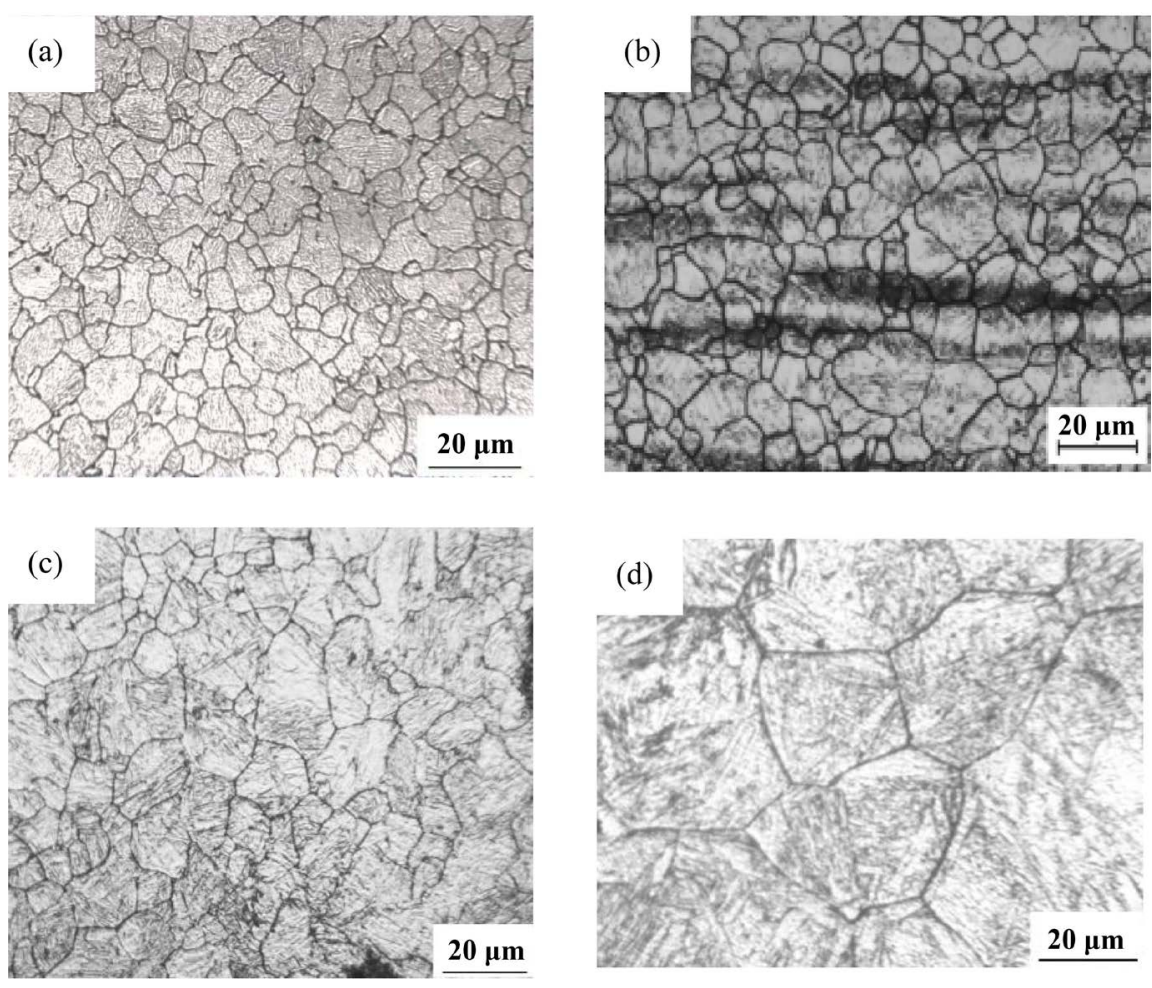

Figure 1. Original austenite crystal morphology at each heating temperature of $30 \mathrm{~min}$. (a) $950^{\circ} \mathrm{C}$; (b) $1000^{\circ} \mathrm{C}$; (c) $1050^{\circ} \mathrm{C}$; (d) $1100^{\circ} \mathrm{C}$. 
rises to $1050^{\circ} \mathrm{C}$, the content of $\mathrm{Nb}$ and $\mathrm{Ti}$ dissolved in austenite increases, and the content of undissolved $\mathrm{Nb}$ and Ti gradually decreases, the nailing effect on austenite weakened, and a few grains grew up abnormally [4]. When the heating temperature rises to $1150^{\circ} \mathrm{C}$, the austenite grains are coarsened obviously, but relatively uniform, with an average size of approximately $49 \mu \mathrm{m}$. This is because when the temperature is greater than $1150^{\circ} \mathrm{C}$, the carbon nitride of the micro-alloy element niobium and titanium gradually dissolves in austenite, so that $1150^{\circ} \mathrm{C}$ becomes a critical heating temperature, when the heating temperature is higher than this temperature, Carbon nitride dissolved in austenite, Some grain boundary lose "nails" and begin to move, especially small grains. The surface free energy is large and it is easier to move in the direction of the crystal. The large grains grow by swallowing the small grains, which causes the roughening of austenite grains [5]. Figure 1 shows that austenite grain size changes have basically gone through three stages: the small and uniform phase of grains, the mixing phase where some grains grow too large, and the coarse but relatively uniform phase of grains.

At the same insulation time, the relationship between quenching heating temperature and austenite average grains is shown in Figure 2(a): It can be seen that when the insulation time is fixed, the average grain size increases exponentially with the increase of heating temperature; At a certain heating temperature, the relationship between the insulation time and the average grain size of the austenite is shown in Figure 2(b): It can be seen that when the heating temperature is fixed, the average grain size increases parabolic with the extension of the insulation time. The effect of heating temperature on average grain size is greater than that of insulation time.

\subsection{Establishment of Grain Growth Mathematical Model for Q1030 Steel}

From the above experiments, it can be seen that the heating temperature and the insulation time will have a certain impact on the growth of austenitic grains in experimental steel. Of course, the influence of initial grain size on austenitic
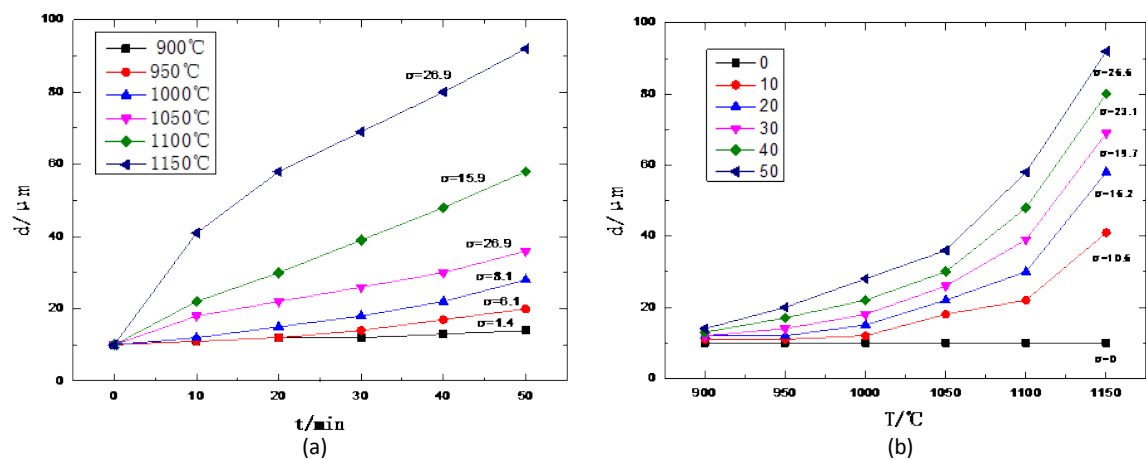

Figure 2. Effect of heating temperature and insulation time on the average grain size of austenite. (a) Effect of heating temperature on grain size (b) Effect of insulation time on grain size. 
grain growth is inevitable. Therefore, if the austenite grain growth law is systematically studied, it is necessary to consider the three factors that affect the heating temperature $(T)$, the insulation time $(T)$, and the average diameter of the initial grain $\left(d_{0}\right)$.

Sellar et al. proposed a mathematical model describing the grain growth law of C-Mn steel in the 1970s. In recent years, many scholars in China have also carried out this work one after another [6]. At present, the model of predicting austenite grain growth law in isothermal process mostly uses Sellars model and Anelli improved model [7] [8], respectively:

$$
\begin{aligned}
& d^{n}-d_{0}^{n}=A t \exp (-Q / R T) \\
& d-d_{0}=B t^{m} \exp (-Q / R T)
\end{aligned}
$$

Formula (1) takes into account the grain growth index $n$, and formula (2) takes into account the time index $\mathrm{m}$. Both equations are based on certain experimental data [9] Taking into account the grain growth index $n$ and the time index $m$, a more reasonable model of the grain growth law can be obtained, as shown in Equation (3):

$$
d^{n}-d_{0}^{n}=A t^{m} \exp (-Q / R T)
$$

In the formula, $d$ is the average diameter of the final grain $(\mu \mathrm{m}) ; d_{0}$ is the average diameter of the initial grain $(\mu \mathrm{m}) ; t$ is the heat preservation time (min); $T$ is the heating temperature $(\mathrm{K}) ; R$ is the molar gas constant; $Q$ is the grain growth activation energy ( $/ \mathrm{mol}) ; A, n, B$, and $m$ are experimental constants.

Take the logarithm on both sides of the Equation (3) and get:

$$
\ln \left(d^{n}-d_{0}^{n}\right)=\ln A+m \ln t-Q / R T
$$

There are four unknowns $m, n, A$ and $Q$ in Equation (4), which can not be determined directly by linear regression. We first set $n$ values, such as $n=1.0$, 1.5, 2.0, 2.5, 3.0, 3.5, 4.0, to determine $M, Q$, and $A$ values by fitting experimental data.

Equation (4), when $T$ is a fixed value, partial derivatives are found for $\ln t$; When $T$ is a fixed value, the partial derivatives for $1 / T$ are obtained by obtaining (5) and (6), respectively, as follows:

$$
\begin{aligned}
& m=\partial\left[\ln \left(d^{n}-d_{0}^{n}\right)\right] /\left.\partial(\ln t)\right|_{T} \\
& Q=-R \partial\left[\ln \left(d^{n}-d_{0}^{n}\right)\right] /\left.\partial(1 / T)\right|_{t}
\end{aligned}
$$

Linear regression of $\ln \left(d^{n}-d_{0}{ }^{n}\right)$ and $\partial(\ln t), \ln \left(d^{n}-d_{0}{ }^{n}\right)$ and $\partial(1 / T)$ respectively, under the condition of setting $n$ value, $M$ and $Q$ values can be obtained, and the $M$ and $Q$ values are brought into the Equation (4) to calculate the A value.

When $n$ sets different values, the error values of $M, Q$, and $A$ are calculated, respectively. The sum of the squares of the errors is a function of $n$, and the goal of optimizing the sum of the regression errors is the minimum. By the method of function fitting, the relationship between the error square and the change of $n$ 
value is obtained. After calculation, when $n=2.503$, the square sum of the error is minimal and the $n$ value is determined, the $M, Q$, and $A$ values are recalculated using the above method.

When $n=2.503$, the relationship between $\ln \left(d^{n}-d_{0}{ }^{n}\right)$ and $\partial(1 / T)$ is shown in Figure 3, and the relationship between $\ln \left(d^{n}-d_{0}{ }^{n}\right)$ and $\partial(\ln t)$ is shown in Figure 4, and $m=1.33$ is calculated. $Q=349.2213 \mathrm{kj} / \mathrm{mol}, A=3.85 \times 1015$. Therefore, under isothermal conditions, the austenitic grain growth model of Q1030 steel is:

$$
d^{2.503}-d_{0}^{2.503}=3.85 \times 10^{15} t^{1.33} \exp (-349221.3 / R T)
$$

Figure 5 is a comparison of austenitic grain size measurements and calculated values at different temperatures for insulation time $30 \mathrm{~min}$. It can be seen that there is a good consistency between the two, and the error between the calculated value and the measured value does not exceed $8 \%$. The explanatory formula (7) can objectively reflect the isothermal growth law of austenite grains and has important reference value.

The above grain growth model can only describe the average size changes of grains, but in fact, the growth of grains may have serious heterogeneity during the growth of grains, and a few grains will grow up abnormally. This is because during the heating process, after the austenite transformation occurs, the grain boundary migrates under the driving force of reducing the free energy of the interface, resulting in the growth of the grain. At the same time, the precipitation phase particles have a certain effect on the grain boundary migration through the "Pinning effect" of the grain boundary [9] [10].

The more phase particles are precipitated, the smaller the radius, the greater the "Pinning effect" resistance generated, and the better the effect of impeding the growth of grains [11] [12].

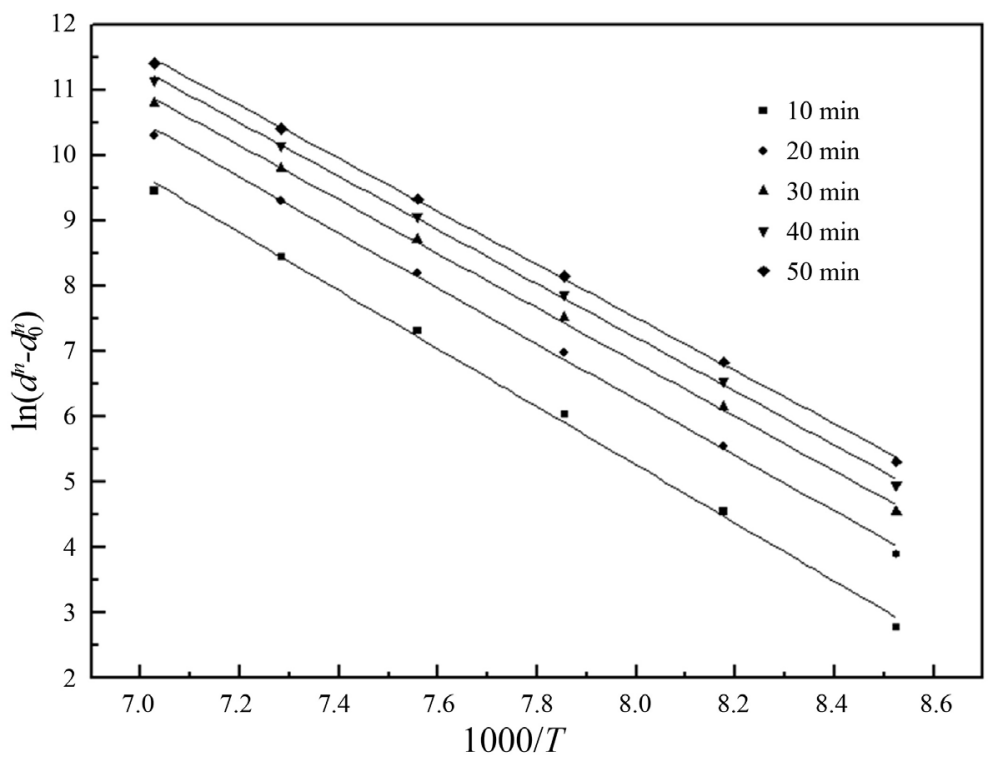

Figure 3. Relation curve between $\ln \left(d^{n}-d_{0}{ }^{n}\right)$ and $1 / T$ at different insulation times. 


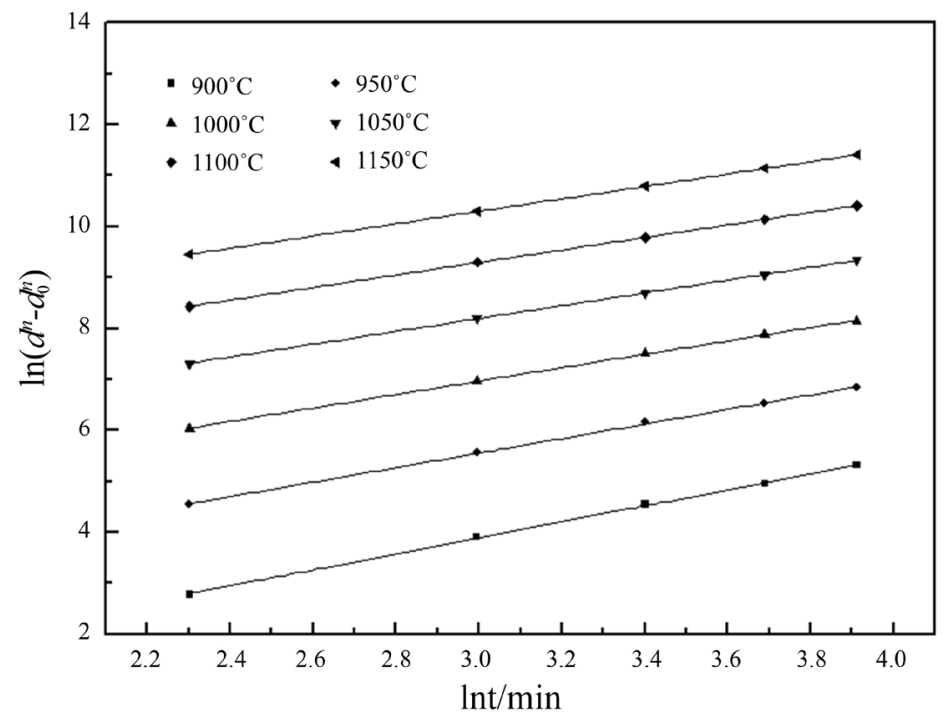

Figure 4. Relationship curve between $\ln \left(d^{n}-d_{0}{ }^{n}\right)$ and $\ln t$ at different heating temperatures.

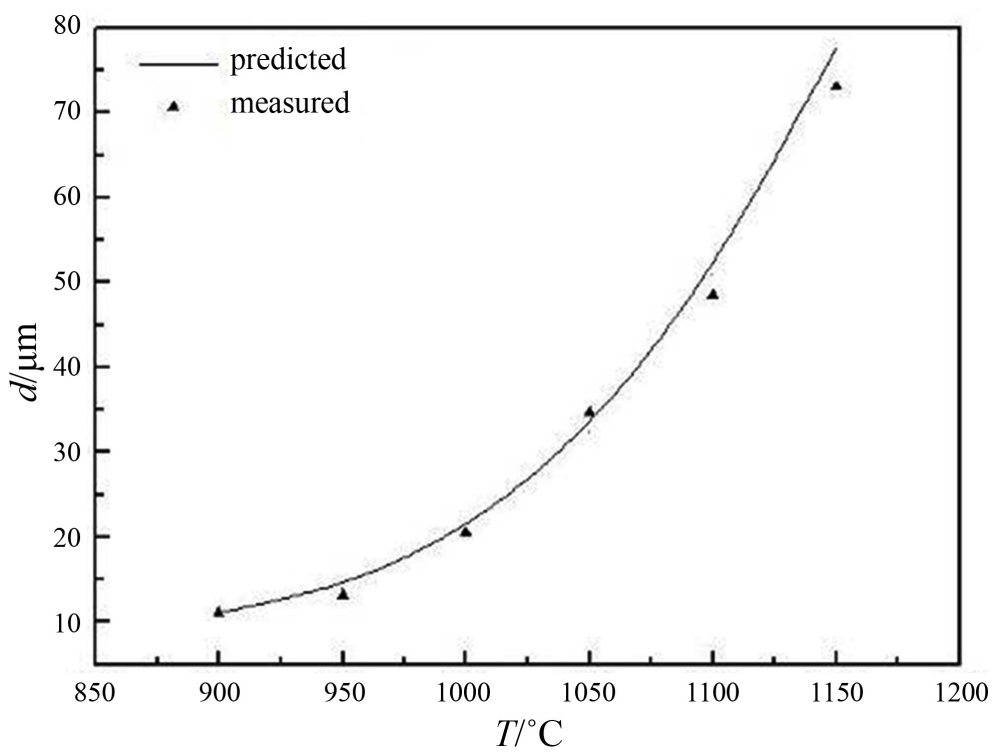

Figure 5. Calculated and measured average size of austenite grains.

\section{Effect of Quenching Temperature on the Microstructure of Q1030 Steel}

It can be seen from Figure 6 that when the quenching heating temperature is $880^{\circ} \mathrm{C}$, due to the low austenitizing temperature, the amount of carbon and alloying elements dissolved into austenite is relatively small, reducing the hardenability of steel [13] [14], In the subsequent cooling process, there was a certain amount of ferrite and bainite formation, and the proportion of martensite tissue was relatively small. At the same time, because the original austenite grain is small, the resulting martensite strip beam is short and narrow, and the directionality is not obvious. When the quenching heating temperature reaches $950^{\circ} \mathrm{C}$, 

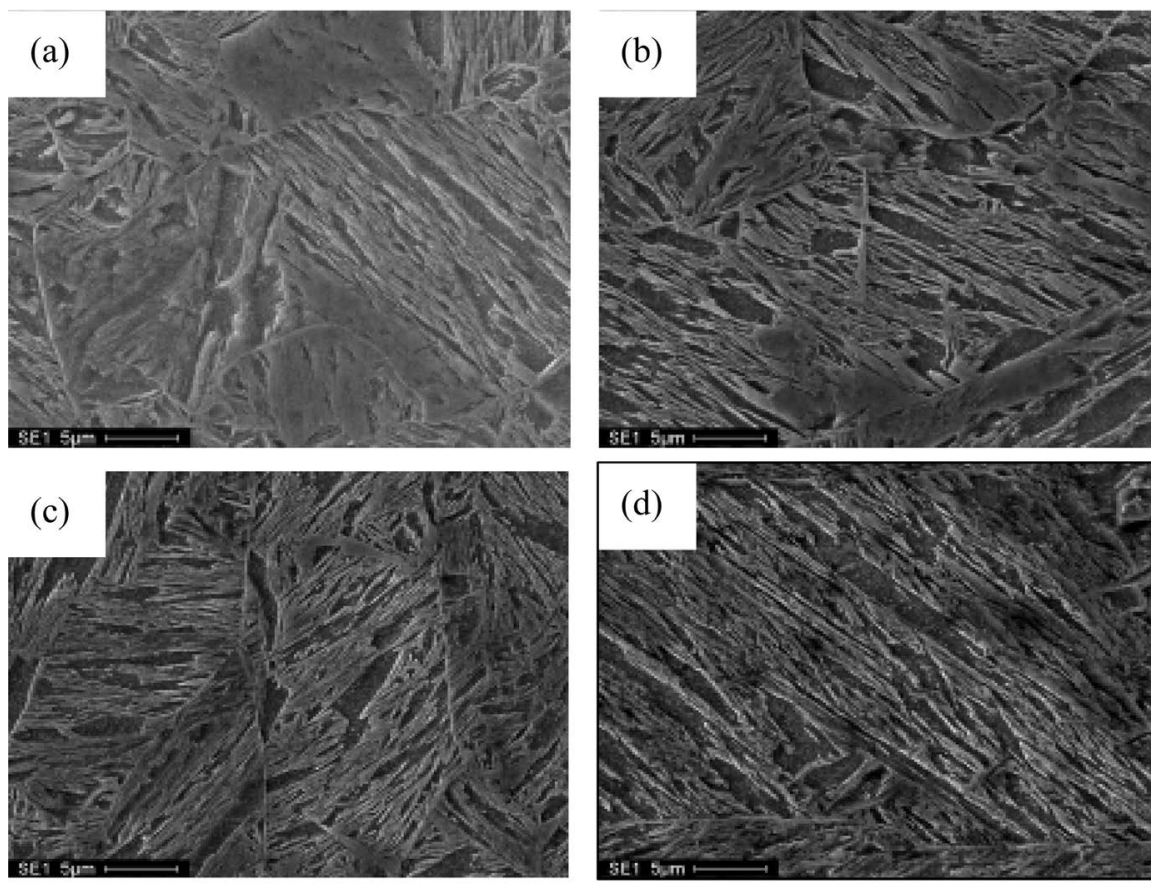

Figure 6. Tissue pictures of Q1030 heat treatment at different austenitic temperature for insulation times $30 \mathrm{~min}$. (a) $880^{\circ} \mathrm{C}$; (b) $950^{\circ} \mathrm{C}$; (c) $1000^{\circ} \mathrm{C}$; (d) $1150^{\circ} \mathrm{C}$.

the proportion of martensite in the tissue increases significantly. When the temperature continues to rise to $1000^{\circ} \mathrm{C}$, due to the coarsenization of some austenite grains and the full dissolution of alloy elements, The resulting martensite strip beam becomes wider and longer, and the strip beam is regular and directional. When the heating temperature rises to $1150^{\circ} \mathrm{C}$, with the increase of quenching temperature, the size of austenite grains increases, and the size of the strip beam obtained after quenching increases accordingly [15]. The austenite grain and martensite strip bundles are severely coarse, the grain boundary is clear, and the austenite grains are divided into several parts by different orientation martensite strips. From this it appears that although the chemical composition of the steel has not changed, However, the different quenching temperature has important influence on the microstructure of Q1030 steel. Therefore, it will lead to great differences in mechanical properties.

\section{Effect of Quenching Temperature on Mechanical Properties of Q1030 Steel}

As can be seen from Figure 7, when quenching at $880^{\circ} \mathrm{C}-950^{\circ} \mathrm{C}$, with the increase of austenitizing temperature, the hardness and strength of Q1030 steel gradually increase, reaching a maximum of $950^{\circ} \mathrm{C}$; At $950^{\circ} \mathrm{C}$, the maximum value was reached, of which the Rockwell hardness was 46HRC and the yield strength was $1160 \mathrm{MPa}$; During quenching at $950^{\circ} \mathrm{C}-1100^{\circ} \mathrm{C}$, the hardness and strength of Q1030 steel gradually decreased with the increase of austenitizing temperature.

This is because when quenching at $880^{\circ} \mathrm{C}-950^{\circ} \mathrm{C}$, with the increase of the 


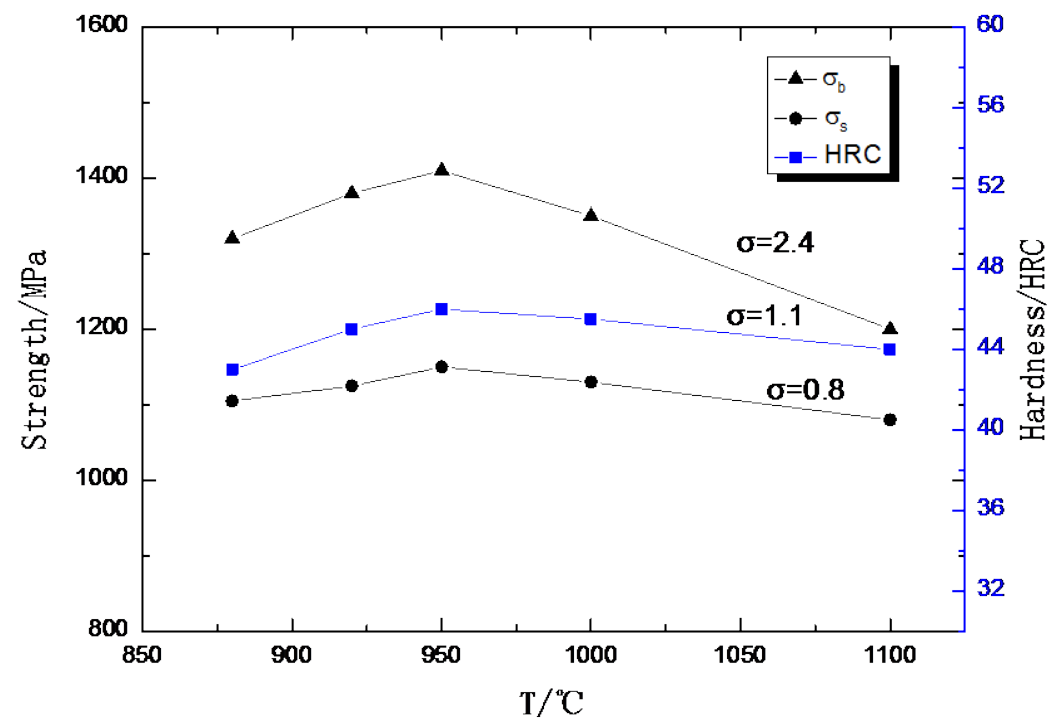

Figure 7. Strength and hardness of Q1030 steel at different austenitic temperatures after 30 min insulation.

heating temperature, the amount of carbide dissolved into the austenite by the alloy element increases, the alloying degree in the austenite increases, and the carbon and alloy elements in the martensite increase after quenching; Moreover, at higher heating temperature, due to the dissolution of carbon and alloy elements, the stability of the overcooled austenite is increased, the hardenability of the steel is enhanced, and the martensite tissue content of the hardened steel is increased. Therefore, the martensite obtained by quenching at a higher austenite temperature has higher hardness and strength. During quenching at $950^{\circ} \mathrm{C}$ $1100^{\circ} \mathrm{C}$, with the increase of heating temperature, the austenite grain and martensite strip bundles were significantly coarsely coarser, so the hardness and strength of the steel decreased with the increase of heating temperature.

\section{Conclusions}

1) The carbonitrides of microalloying elements niobium and titanium in Q1030 steel will gradually dissolve in the austenite with the increase of the quenching heating temperature, gradually losing the nail effect on the grain boundary, so the grain will gradually increase with the temperature. When the temperature is lower than $1150^{\circ} \mathrm{C}$, the grain grows less obvious. When the temperature is higher than $1150^{\circ} \mathrm{C}$, because most of the carbon nitride is dissolved in austenitic, many grain boundaries lose their "nailing" function" and begin to move. This causes the rapid coarsening of austenite grains.

2) In this paper, the quenching heating system of Q1030 ultra high strength steel is studied in a series of laboratories; the grain growth model is established, and the regression calculation method is introduced to verify the correctness of the model.

At different heating temperatures and thermal insulation times, the austenitic grain growth model of Q1030 steel is: 


$$
d^{2.503}-d_{0}^{2.503}=3.85 \times 10^{15} t^{1.33} \exp (-349221.3 / R T)
$$

where $d$ is the average diameter of the final grain $(\mu \mathrm{m}) ; d_{0}$ is the average diameter of the initial grain $(\mu \mathrm{m})$; $t$ is the heat preservation time ( $\mathrm{min}) ; T$ is the heating temperature (K); $R$ is the molar gas constant.

3) The quenching temperature has a great influence on the microstructure and mechanical properties of Q1030 steel. During quenching at $880^{\circ} \mathrm{C}-950^{\circ} \mathrm{C}$, with the increase of austenitic temperature, the hardness and strength of Q1030 steel gradually increased, and the hardness and strength reached a maximum at $950^{\circ} \mathrm{C}$. During quenching at $950^{\circ} \mathrm{C}-1100^{\circ} \mathrm{C}$, the hardness and strength of Q1030 steel gradually decreased with the increase of austenitic temperature.

\section{Conflicts of Interest}

The authors declare no conflicts of interest regarding the publication of this paper.

\section{References}

[1] Hui, W.J., Dong, H., et al. (2002) Effect of Quenching Temperature on the Mechanical Properties of Dihejingaoqiang. Metal Heat Treatment, 27, 14-16.

[2] Zhang, Z.B., Sun, X.J., Liu, Q.Y., et al. (2008) Study on the Law of the Growth of Low Carbon Steel Austenite Grains during the Isothermal Process. Journal of Material Heat Treatment, 29, 89-92.

[3] Zhao, Y.Q., et al. (2019) Effect of Quenching Temperature on Microstructure and Mechanical Properties of $780 \mathrm{MPa}$ Grade Hydropower Steel. Special Steel, 40, 46-50.

[4] Hui, J., Yu, Y., Wang, C., Wang, L, et al. (2014) Titanium Microalloying Hot Rolling Austenite Grain Coarsening Behavior. Journal of Material Heat Treatment, 35, $140-145$.

[5] Yang, X.L. (2002) Effect of Heating Temperature on Solid Solution and Grain Growth of Second Phase Particles in Pipeline Steel. Iron and Steel Vanadium Titanium, 23, 11-15.

[6] Yue, Z.X., Zhang, L.W., Liao, S.L., et al. (2008) Study on the Law of Austenite Grain Growth of GCr15 Steel. Journal of Material Heat Treatment, 29, 94-97.

[7] Devadas, C. (1991) The Thermal and Metallurgical State of Steel Strip during Hot Rolling: Part 3. Microstructural Evolution. Metallurgical Transactions A, 22, 335-342. https://doi.org/10.1007/BF02656802

[8] Raghunathan, N. and Sheppard, T. (1986) Microstructural Development during Annealing of Hot Rolled Al-Mg Alloys. Materials Science and Techonology, 6, 542-547. https://doi.org/10.1179/mst.1989.5.6.542

[9] Chen, L.Q., Sui, F.L. and Liu, X.H. (2009) Inconel 718 Alloy Blank Crystal Growth Model during Rough Rolling Heating. Journal of Metals, 45, 1242-1248.

[10] Moon, J., Kim, S., Lee, J. and Lee, C. (2007) Limiting Austenite Grain Size of TiNContaining Steel Considering the Critical Particle Size. Scripta Materialia, 56, 1083-1086. https://doi.org/10.1016/j.scriptamat.2007.02.025

[11] Fernández, J., Illescas, S. and Guilemany, J.M. (2007) Effect of Microalloying Elements on the Austenitic Grain Growth in a Low Carbon HSLA Steel. Materials Letters, 61, 2389-2392. 
[12] Han, L.Z., Chen, R.K., Gu, J.F., et al. (2009) X12CrMoWVNbN10-1-1 Ferrite Heat-Resistant Steel Austenite Grain Growth Behavior Study. Journal of Metals, 45, 1446-1250.

[13] Hui, W.J., Dong, H., Wang, M.Q., et al. (2002) Effect of Quenching Temperature on the Mechanical Properties of Low-Alloy High-Strength Steel of Cr-Mo-V Series. Metal Thermal Treatment, 27, 14-16.

[14] Wan, D.C., Yu, W., Li, X.L., et al. (2012) Effect of Quenching Temperature on Microstructure and Mechanical Properties of $550 \mathrm{MPa}$ Thick Steel Plate. Journal of Metals, 48, 455-460. https://doi.org/10.3724/SP.J.1037.2011.00722

[15] Duan, Z.T., Li, Y.M., Zhu, F.X., et al. (2012) Effect of Quenching Temperature on the Microstructure and Mechanical Properties of Q690D High Strength Steel. Metal Thermal Treatment, 37, 81-84. 